\title{
Cataract in a patient with the Alport syndrome and diffuse Leiomyomatosis
}

\author{
Catarata em paciente com sindrome \\ de alport e leiomiomatose difusa
}

Luis Santiago - Cabán', Cristóbal Cruz², Natalio J. Izquierdo²

\begin{abstract}
We describe a case of painless progressive loss of vision in a 15 years old male patient with Alport syndrome and diffuse Leiomyomatosis. After a comprehensive history and ocular examination, a diagnosis of bilateral posterior subcapsular cataracts was given. Patient underwent cataract extraction. His best corrected post-operative visual acuity was 20/25 in both eyes. We conclude that posterior subcapsular cataracts may lead to painless and progressive loss of vision in patients with Alport syndrome and Diffuse Leiomyomatosis
\end{abstract}

Keywords: Nephritis, hereditary/complications; Nephritis, hereditary/diagnosis; Leiomyomatosis/diagnosis; Cataract/etiology; Cataract extraction; Eye manifestations

\footnotetext{
'UPR School of Medicine, San Juan, Puerto Rico;

2Department of Ophthalmology, University of Puerto Rico, Medical Sciences Campus.
} 


\section{INTRODUCTION}

$\mathbf{P}$ atients with the Alport syndrome (AS) have a hereditary progressive nephritis associated with sensorineural deafness and ocular manifestations ${ }^{(1-2)}$. It has been suggested that three out of the following criteria must be present in order to establish a clinical AS diagnosis: 1) positive family history of hematuria with or without renal failure; 2 ) characteristic electron microscopic changes of the glomerular basement membrane on renal biopsy; 3) ophthalmic signs; and 4) high-tone sensorineural hearing impairment ${ }^{(3)}$.

Ocular findings in patients with AS vary. Previous studies have reported that patients with the AS may have lenticular findings including: anterior lenticonus ${ }^{(245)}$; anterior and posterior polar opacities; anterior and posterior subcapsular cataracts; cortical, coronal and lamellar cataracts ${ }^{(2)}$; and fleck retinopathy ${ }^{(2)}$.

Occasionally, patients with the Alport syndrome have associated diffuse Leiomyomatosis ${ }^{(6.7)}$. The latter is characterized by benign nodular smooth muscle tumor of esophagus, genital tract and tracheobronchial tree ${ }^{(8)}$. Dysphagia, postprandial vomiting, substernal or epigastric pain, bronchitis, dyspnea, cough and stridor are some of the symptoms that characterize Leiomyomatosis of the esophagus and tracheobronchial tree. Diagnosis is confirmed by computed tomography scanning or magnetic resonance imaging of the systems involved.

Previous studies have reported that the Alport syndrome may be inherited as an X-linked trait ${ }^{(9)}$. Other studies suggest an autosomal recessive inheritance pattern for patients with the syndrome ${ }^{(10-11)}$.

We report on a patient who had painless and progressive loss of vision due to posterior subcapsular cataracts in both eyes that could be part of the Alport syndrome with diffuse Leiomyomatosis.

\section{Case Report}

This is the case of a 15 years-old male patient who carries a diagnosis of the AS. He had painless progressive loss of vision of both eyes. There was no history of trauma. Patient had progressive hearing loss. Laboratory studies undertaken on february 1, 2008 confirm the presence of both gross (blood $3+$ ) and microscopic hematuria (over 50 RBC's per power field). Patient also has moderate restrictive ventilator defect with a reduced forced vital capacity. Fiberoptic bronchoscopy performed on march, 2002, showed tracheomalacia due to prominent post-tracheal wall with complete airway closure on expiration, which accounts for

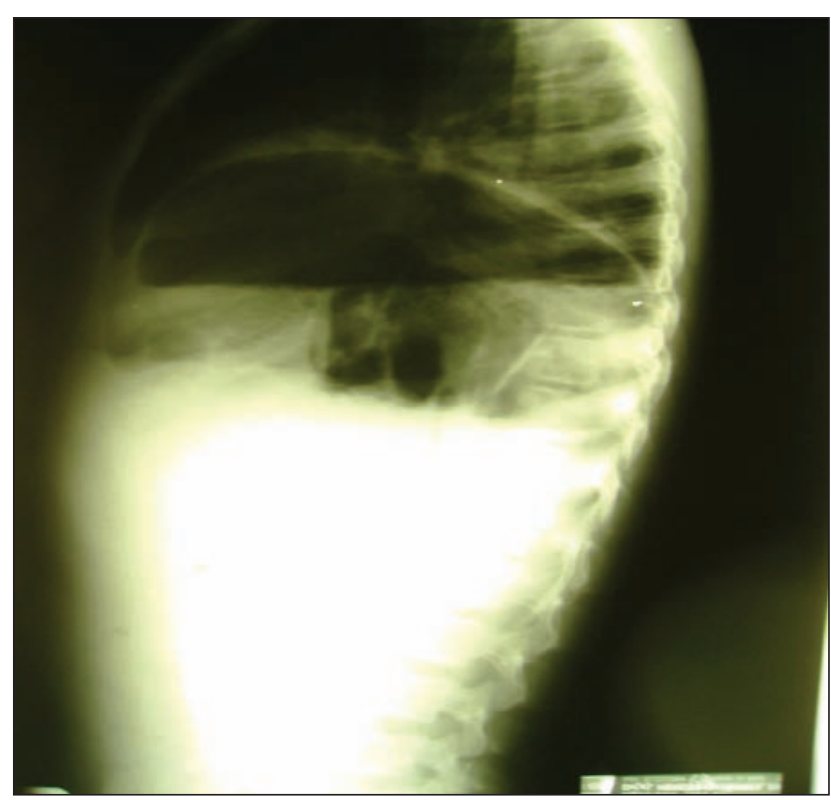

Figure 1: Lateral Chest X-ray of the patient showing gastric bubble above diaphragm secondary to esophagectomy and partial gastrectomy

the above mentioned restrictive ventilator defect.

Patient had a four year history of progressive dysphagia accompanied with constipation in the past. After extensive imaging, leiomyomas were found along the gastrointestinal tract, mainly in the esophagus and anus. In 2001, patient underwent esophagectomy and partial gastrectomy (Figure 1), which corrected the dysphagia. Removal of anal leiomyomas relieved the constipation. Pathologic report confirmed the diagnosis. After esophagectomy and partial gastrectomy, patient was treated with oral prednisone for two months. Upon questioning mother and after chart review, the dose of prednisone remains unknown.

Patient's mother underwent cataract surgery when she was 17 years old. She had anal and vaginal leiomyomas. She had no history of hematuria. There are no maternal uncles with the disease.

Upon eye examination patient's best corrected visual acuity was 20/100 in both eyes. Corneas were clear. As depicted in Figures 2 and 3, patient had posterior subcapsular cataracts in both eyes. Indirect ophthalmoscopy showed healthy optic nerves, intact vessels, maculae and peripheries. There was no evidence of macular or mid-peripheral fleck retinopathy.

Patient underwent cataract surgery with intraocular lens implantation in both eyes during february,2008. Due to his respiratory disease, surgery was done in a semi-sitting position under topical anesthesia. Best-corrected post-opera- 


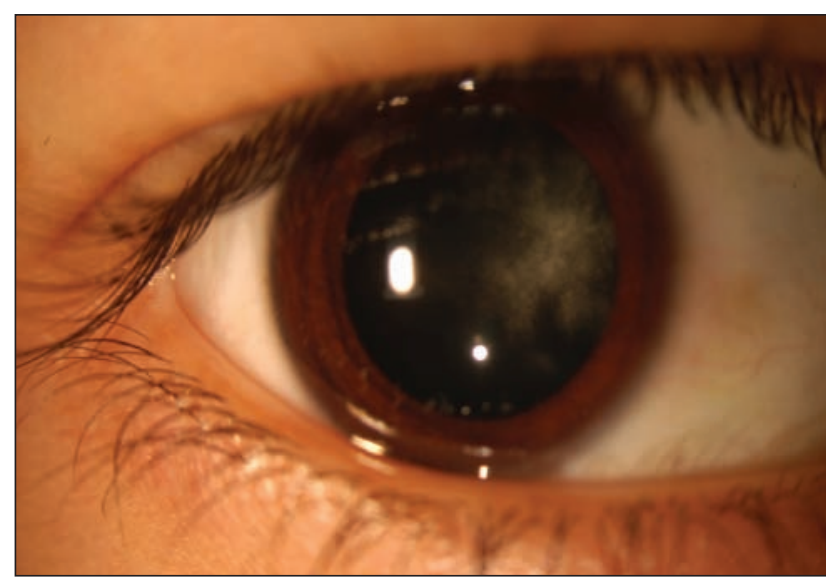

Figure 2: Posterior subcapsular cataract of right eye

tive visual acuity was $20 / 20$ in both eyes with a $+1.50-1.00 \mathrm{x}$ 15 and -0.50 sphere in the right and left eye respectively.

\section{Discussion}

Patients with AS develop progressive renal failure, deafness and ocular changes due to disorders of basement membranes ${ }^{(12)}$.

Ocular findings in patients with the syndrome include: anterior lenticonus, anterior and posterior polar cataracts, corneal arcus and posterior polymorphous dystrophy, pigment dispersion syndrome, macular pigmentation, salt and pepper-like retinopathy, fleck retinopathy, and tortuosity of retinal blood vessels. ${ }^{(2.5)}$ Our patient had posterior subcapsular cataracts in both eyes.

Several genetic causes lead to the syndrome, including X-linked and autosomal recessive patterns. The former has been associated with the rare manifestation of AS with diffuse leiomyomatosis. Obligate carriers in various hereditary eye diseases have signs compatible with the syndrome ${ }^{(13)}$. Further, lens opacities have been described in carriers of X-linked Alport syndrome ${ }^{(13)}$. Interestingly, our patient's mother underwent cataract surgery during adolescence and had anal and vaginal leiomyomas. As described in previous studies, the COL4A5 and COL4A6 genes, located head to head in Xq22 encoding the alpha 5 and alpha 6 (IV) chains, are responsible for the abnormalities present in this rare manifestation ${ }^{(15)}$.

Clinical findings in this patient are compatible with the diagnosis of AS with DL. Studies associate the development of posterior subcapsular cataracts in this syndrome with prolonged use of steroids ${ }^{(5)}$. Our patient used steroids for two months following esophagectomy

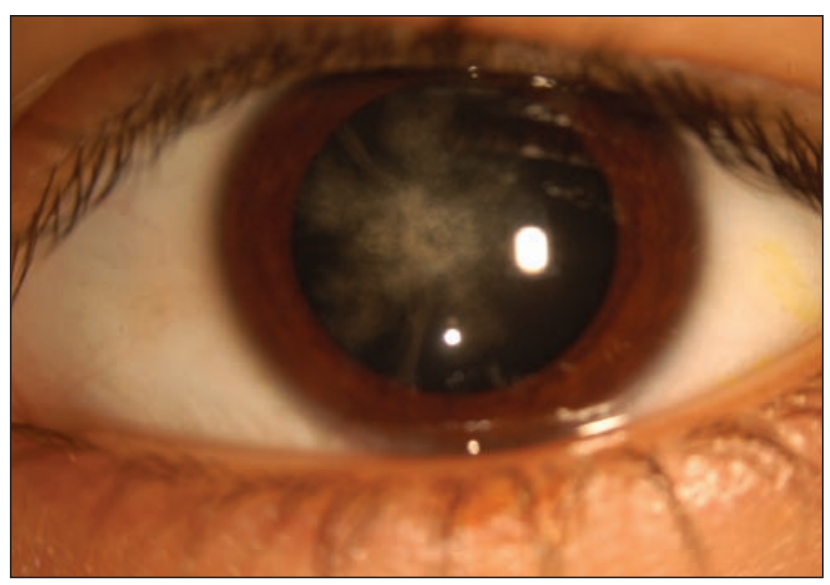

Figure 3: Posterior subcapsular cataract of left eye

and partial gastrectomy. For this reason, the possibility of developing cataracts as a consequence of steroid use in this patient is low.

In conclusion, patients with the AS with DL may have painless progressive vision loss due to posterior subcapsular cataract associated with the syndrome. Even though cataracts have been reported in patients with AS without DL, to our knowledge posterior subcapsular cataracts have not been previously reported in patients with the syndrome and diffuse Leiomyomatosis. Further, to our knowledge, ocular findings such as juvenile cataracts in obligate carriers of AS with DL had not been reported. Cataract surgery in young patients with AS and DL with decreased respiratory function are challenging.

\section{Acknowledgement}

We thank Zelia M. Correa, MD, Ph D, from the University of Cincinnati College of Medicine, for translating parts of the text to Portuguese.

\section{Resumo}

Nós descrevemos o caso de perda visual progressiva indolor em um paciente de 15 anos, Isexo masculino, com Sindrome de Alport e Leiomiomatose difusa. Após história completa e exame oftalmológico, foi feito o diagnóstico de catarata subcapsular posterior bilateral. O paciente foi submetido à cirurgia de catarata. Nós concluímos que cataratas subcapsulares posteriores podem levar a perda visual progressiva e indolor em pacientes com Síndrome de Alport e Leiomiomatose Difusa.

Descritores: Nefrite hereditária/complicações; Nefrite hereditária/diagnóstico; Leiomiomatose/diagnóstico; Catarata/etiologia; Extração de catarata; Manifestações oculares 


\section{RefERENCES}

1. Gubler M, Levy M, Broyer M, Naizot C, Gonzales G, Perrin D, Habib R. Alport's syndrome: a report of 58 cases and a review of the literature. Am J Med. 1981;70(3):493-505.

2. Colville DJ, Savige J. Alport syndrome. A review of the ocular manifestations. Ophthalmic Genet. 1997;18(4):161-73.

3. Flinter F, Chantler C. Alport's syndrome: inheritance and clinical features. In: Spitzer A, Avner E, editors. Inheritance of kidney and renal tract disease. Boston: Kluwer Academic;1990. p.107-20.

4. Govan JA. Ocular manifestations of Alport's syndrome: a hereditary disorder of basement membranes? $\mathrm{Br} \mathrm{J}$ Ophthalmol. 1983;67(8):493-503.

5. Jacobs M, Jeffrey B, Kriss A, Taylor D, Sa G, Martin Barrat T Ophthalmologic assessment of young patients with Alport Syndrome. Ophthalmology. 1992;99(7):1039-44.

6. Garcia-Torres R, Orozco L. Alport-leiomyomatosis syndrome: An update. Am J Kidney Dis. 1993;22(5):641-8.

7. Anker MC, Arnemann J, Neumann K, Ahrens P, Schmidt H, König R. Alport syndrome with diffuse leiomyomatosis. Am J Med Genet A. 2003;119(3):381-5.

8. Miner J H. Alport syndrome with diffuse leiomyomatosis when and when not? Am J Pathol. 1999;154(6):1633-5.

9. Flinter FA, Cameron JS, Chantler C, Houston I, Bobrow M. Genetics of classic Alport's syndrome. Lancet. 1988;2(8618):1005-7.
10. Feingold J, Bois E. Genetics of Alport Syndrome. Pediatr Nephrol. 1987;1(3):436-8.

11. Feingold J, Chompret A, Broyer M, Gubler MC, Grünfeld JP. Genetic heterogeneity of Alport syndrome. Kidney Int. 1985;27(4):672-7.

12. Kashtan CE. Alport syndrome. An inherited disorder of renal, ocular, and cochlear basement membranes. Medicine. 1999;78(5):338-60.

13. Charnas LR, Bernardini I, Rader D, Hoeg JM, Gahl WA Clinical and laboratory findings in the oculocerebrorenal syndrome of Lowe, with special reference to growth and renal function. N Engl J Med. 1991;324(19):1318-25.

14. Friedman NJ, Keiser PK, and Trattler WB. Review of ophthalmology. Philadelphia (PA): Elsevier Saunders; 2005. p.106

15. Garcia-Torres R, Cruz D, Orozco L. Heidet L. Gubler MC Alport sindrome and diffuse leiomyomatosis. Clinical aspects, pathology, molecular biology and extracellular matrix studies. A synthesis. Nephrologie. 2000;21(1):9-12.

\section{MANUSCRIPT CoRresPondence: \\ Natalio J. Izquierdo, MD \\ 369 De Diego St - Torre San Francisco Suite 310 \\ San Juan, Puerto Rico 00923}

